\title{
Preparedness of neurosurgery graduates for neuroendovascular fellowship: a national survey of fellowship programs
}

\author{
Nohra Chalouhi, MD, ${ }^{1}$ Mario Zanaty, MD, ${ }^{1}$ Stavropoula Tjoumakaris, MD, ${ }^{1}$ Philip Manasseh, MPH, ${ }^{1}$ \\ David Hasan, MD, ${ }^{2}$ Ketan R. Bulsara, MD, ${ }^{3}$ Robert M. Starke, MD, ${ }^{1}$ Kevin Lawson, MD, ${ }^{1}$ \\ Robert Rosenwasser, MD, ${ }^{1}$ and Pascal Jabbour, MD'
}

\begin{abstract}
'Department of Neurosurgery, Thomas Jefferson University and Jefferson Hospital for Neuroscience, Philadelphia, Pennsylvania; 2Department of Neurosurgery, University of lowa, lowa City, lowa; and ${ }^{3}$ Department of Neurosurgery, Yale and New Haven Hospital, New Haven, Connecticut
\end{abstract}

OBJECT Endovascular interventions have become an essential part of a neurosurgeon's practice. Whether endovascular procedures have been effectively integrated into residency curricula, however, remains uncertain. The purpose of this study was to assess the preparedness of US neurosurgery graduate trainees for neuroendovascular fellowship.

METHODS A multidomain, global assessment survey was sent to all directors/faculty of neuroendovascular fellowship programs involved in training of US neurosurgery graduates. Surveyees were asked to assess trainees as they entered fellowship.

RESULTS The response rate was 78\% (25/32). Of respondent program directors, 38\% reported that new fellows did not know the history and imaging of the patient and $50 \%$ were unable to formulate an appropriate treatment plan. As many as $79 \%$ of fellows were unfamiliar with endovascular devices and $75 \%$ were unfamiliar with angiographic equipment. Furthermore, $58 \%$ of fellows were unable to perform femoral access, $54 \%$ were unable to perform femoral closure, $79 \%$ were unable to catheterize a major vessel, $86 \%$ were unable to perform a 4 -vessel angiogram, and $100 \%$ were unable to catheterize an aneurysm. Additionally, program directors reported that over $50 \%$ of fellows could not recognize neurovascular anatomy and $54 \%$ could not recognize/classify vascular abnormalities. There was an overall agreement that fellows demonstrated professionalism and interest in research and had good communication/clinical skills.

CONCLUSIONS The results of this study suggest potential gaps in the training of neurosurgery residents with regard to endovascular neurosurgery. In an era of minimally invasive therapies, changes in residency curricula may be needed to keep pace with the ever-changing field of neurosurgery.

http://thejns.org/doi/abs/10.3171/2014.10.JNS141564

KEY WORDS endovascular; fellowship; neurosurgery; residency; training; interventional neurosurgery

$\mathrm{V}$ ASCULAR neurosurgery is a rapidly evolving field in which endovascular interventions have become an essential part of daily practice. For vascular neurosurgeons, dual training in microsurgical and endovascular techniques has become the norm, especially in North America. Today, in addition to microsurgery, neurosurgeons perform endovascular procedures to treat a wide range of intracranial vascular abnormalities, including aneurysms, arteriovenous malformations (AVMs), ischemic stroke, carotid stenosis, and tumors such as retinoblas- toma. ${ }^{1-8,13-15}$ For some vascular disorders, endovascular interventions have shown even higher or at least similar safety/efficacy compared to microsurgery, not to mention that minimally invasive approaches are becoming heavily favored over traditional approaches by patients. ${ }^{12}$

The non-transferability of skills between open and endovascular approaches requires a compensatory increase in exposure to endovascular procedures during training. The already complex open microsurgical procedures coupled with the duty hours restrictions have made it diffi-

ABBREVIATION AVM = arteriovenous malformation.

SUBMITTED July 3, 2014. ACCEPTED October 15, 2014.

INCLUDE WHEN CITING Published online April 3, 2015; DOI: 10.3171/2014.10.JNS141564.

DISCLOSURE The authors report no conflict of interest concerning the materials or methods used in this study or the findings specified in this paper. 
cult for neurosurgery residents to be adequately exposed to endovascular procedures. It is also uncertain whether endovascular procedures have been effectively integrated into residency curricula.

This study assesses the level of preparedness of incoming fellows from US neurosurgery programs to endovascular fellowships and determines potential gaps in training that could be acted upon during residency.

\section{Methods}

A multidomain, global assessment survey was sent electronically to all directors/faculty of neuroendovascular fellowship programs involved in training of US neurosurgery graduates. One survey was sent per program. The list of programs offering endovascular fellowships for neurosurgery residents was taken from the fellowship section of the website of the American Association of Neurological Surgeons.

The survey focused on professionalism, psychomotor ability and independent practice, clinical evaluation and management, and academia and scholarship (Table 1). The survey was kindly provided by the General Surgery Fellowship Council Research Committee and was subsequently adapted to neurosurgery. ${ }^{10}$ The final version included 39 quantitative items and 1 open comment section. Quantitative items used a standard 5-point Likert-style scale. Surveyees were asked to assess trainees as they entered fellowship. The survey was sent electronically to 32 active fellowship program directors of accredited endovascular fellowships in September 2013 (Table 2). The electronic link was accompanied by an introductory statement outlining the goal of the survey, explaining that the survey was completely anonymous, and emphasizing the need to provide an assessment of fellows as they entered fellowship. Three reminders were sent at 1-week intervals to increase the response rate.

Data are presented as mean and range for continuous variables and as frequency for categorical variables.

\section{Results}

The response rate was $78 \%(25 / 32)$.

\section{Professionalism}

Of respondent program directors, 38\% reported that new fellows did not know the history and imaging of the patient they were treating, $46 \%$ arrived unprepared for the procedure, and 50\% were unable to formulate an appropriate treatment plan (Tables 3 and 4). On the other hand, $83 \%$ of trainees were thought to communicate effectively with patients, $76 \%$ to demonstrate ownership toward patients, $88 \%$ to treat ancillary staff with respect, $96 \%$ to treat residents and house staff with respect, and $96 \%$ to demonstrate professional behavior.

\section{Independent/Graduated Practice Domain}

As many as $79 \%$ of respondents felt that fellows were unfamiliar with endovascular devices and $75 \%$ felt that fellows were unfamiliar with the angiographic equipment. Furthermore, $58 \%$ of fellows were unable to perform fem- oral access, 54\% were unable to perform femoral closure, $79 \%$ were unable to catheterize a major vessel, $86 \%$ were unable to perform a 4-vessel angiogram, and $100 \%$ were unable to independently catheterize an aneurysm or an AVM feeder.

Additionally, program directors reported that over 50\% of fellows could not recognize neurovascular anatomy and anatomical variants, and 54\% could not recognize/classify vascular abnormalities, while $52 \%$ were unable to identify early complications. Only $32 \%$ were able to take calls with only occasional consultation with the attending, and $48 \%$ were able to take care of all perioperative issues.

\section{Disease State Expertise Domain}

Program directors noted that $67 \%$ of fellows understood the pathophysiology of the disease, $56 \%$ understood options for treatments and the role and indications for surgery, while $84 \%$ were able to design the correct work-up. Also, $75 \%$ were able to counsel patients regarding the differential diagnosis and the recommendations of care, and $80 \%$ demonstrated clinical maturity to identify features of the potentially critically ill patient, to triage to the appropriate level of care, and to seek senior help in a timely and communicative way. As many as $36 \%$ of fellows did not understand the indications for the procedure, $48 \%$ did not have a good grasp of alternatives for treatment and the areas of controversy, and 44\% did not understand diseasespecific post-surgical or post-radiographic follow-up.

\section{Research/Academic Ability Domain}

There was an overall agreement that fellows demonstrated professionalism and interest in research and had good communication and clinical skills. Specifically, $80 \%$ of fellows showed healthy curiosity in understanding underlying mechanisms, $64 \%$ showed genuine interest in academic projects, $52 \%$ were familiar with recent publications, and $60 \%$ displayed self-initiative in conducting clinical research.

\section{Questionnaire Assessment}

Only $12 \%$ of respondents did not agree that the survey adequately assessed the research question.

\section{Discussion}

Endovascular neurosurgery is probably the most rapidly evolving subspecialty in the field of neurosurgery. It is an attractive subspecialty to neurosurgery residents, driven not only by the emergence of innovative, safe, and effective devices but also by the popularity of minimally invasive approaches among patients. Today, endovascular procedures constitute about $75 \%$ of a vascular neurosurgeon's practice. Neurosurgeons have also taken a prominent role in the field both at the national and the international level. Whether endovascular procedures have been effectively integrated into residency curricula, however, remains uncertain.

The present study evaluated the readiness of graduating neurosurgery residents for neuroendovascular fellowship. The results of the survey suggest potential gaps in the 
TABLE 1. Questionnaire*

\begin{tabular}{|c|c|}
\hline \multicolumn{2}{|c|}{ Professionalism } \\
\hline A & Communicates effectively with his/her patients \\
\hline B & Promptly comes in after hours to evaluate a patient that may need higher level care/ICU transfer \\
\hline C & Demonstrates ownership towards his/her patients \\
\hline D & Treats the ancillary staff with respect \\
\hline $\mathrm{E}$ & Treats the residents and house staff with respect \\
\hline $\mathrm{F}$ & Demonstrates professional behavior \\
\hline & Knows the history and imaging of the patients they are operating upon \\
\hline $\mathrm{H}$ & Arrives to the endovascular suite prepared for the procedure \\
\hline & Formulates a plan of action for patients (inpatient/outpatient) prior to you seeing the patient \\
\hline \multicolumn{2}{|c|}{ Independent/Graduated Practice Domain } \\
\hline \multicolumn{2}{|r|}{$\mathrm{J}$ Is familiar and comfortable with the devices (access devices, closure devices, wires, catheters, etc.) } \\
\hline \multicolumn{2}{|r|}{$\mathrm{K}$ Is familiar and comfortable with the angiography equipment } \\
\hline \multicolumn{2}{|r|}{ L Can obtain femoral access } \\
\hline \multicolumn{2}{|r|}{ M Can perform vascular closure } \\
\hline \multicolumn{2}{|r|}{$\mathrm{N}$ Catheterization of a major vessel safely without me being scrubbed } \\
\hline \multicolumn{2}{|r|}{ O Performs a 4-vessel angiogram safely without me being scrubbed } \\
\hline \multicolumn{2}{|r|}{ P Aneurysm or AVM feeder catheterization safely with me in the room next door } \\
\hline \multicolumn{2}{|r|}{ Q Take calls with only occasional consultation with me and only occasional assistance in the suite for difficult cases } \\
\hline \multicolumn{2}{|r|}{$\mathrm{R}$ Cares for all postoperative issues on our patients } \\
\hline \multicolumn{2}{|r|}{ S Is proficient in recognition of the neurovascular anatomy } \\
\hline \multicolumn{2}{|r|}{ T Can recognize anatomic variants } \\
\hline \multicolumn{2}{|r|}{$\mathrm{U}$ Is proficient in recognition and classification of neurovascular abnormalities } \\
\hline \multicolumn{2}{|r|}{ V Can identify early complications } \\
\hline \multicolumn{2}{|r|}{ W Understands pathophysiology of the disease } \\
\hline \multicolumn{2}{|r|}{ X Understands options for treatments and the role and indications for surgery } \\
\hline \multicolumn{2}{|r|}{ Y Is able to perform an initial outpatient interview and the design of the correct workup } \\
\hline \multicolumn{2}{|r|}{$\mathrm{Z}$ Is able to counsel patients regarding the differential diagnosis and the recommendations for care } \\
\hline \multicolumn{2}{|r|}{ AA Understands indications for procedure and appropriate work-up } \\
\hline \multicolumn{2}{|r|}{$A B$ Has a good grasp of alternatives for treatment and the areas of controversy or lack of consensus } \\
\hline \multicolumn{2}{|r|}{ AC Understands disease-specific post-surgical or post-radiographic follow-up } \\
\hline \multicolumn{2}{|c|}{$\begin{array}{l}\text { AD Demonstrates clinical maturit } \\
\text { care, and to seek senior } h\end{array}$} \\
\hline \multicolumn{2}{|c|}{ Research/Academic Ability Domain } \\
\hline \multicolumn{2}{|r|}{ AE Shows healthy curiosity in understanding underlying mechanisms } \\
\hline \multicolumn{2}{|r|}{ AF Shows a genuine interest in academic projects } \\
\hline \multicolumn{2}{|r|}{ AG Is familiar with recent publications in his/her field of advanced training } \\
\hline & Displays self-initiative in conducting clinical research \\
\hline $\mathrm{Al}$ & Is able to compile and analyze data \\
\hline & Shows understanding of research protocol design \\
\hline AK & Shows understanding of basic statistics \\
\hline $\mathrm{AL}$ & Is capable of writing a coherent manuscript \\
\hline Do you & u think that the survey adequately assesses the research question? \\
\hline Free co & omments regarding any aspect of the readiness of trainees for neuroendovascular fellowship \\
\hline
\end{tabular}

* Respondents were asked to indicate the degree to which they agreed with the above items using a Likert-style scale (choice of one of the following responses: strongly agree, agree, neutral, disagree, strongly disagree).

training of neurosurgery residents with regard to endovascular neurosurgery. Areas where neurosurgery graduates underperformed include trainability, independent ability, decision making, and knowledge of neurovascular anat- omy and abnormalities. For example, over $50 \%$ of graduating neurosurgeons could not achieve femoral access or closure, a task that should typically be mastered during the internship year. Also, over $75 \%$ of trainees were not 
TABLE 2. List of surveyed programs

\begin{tabular}{l}
\hline University of lowa \\
\hline Tulane University \\
\hline Yale and New Haven Hospital \\
\hline Barrow Neurological Institute \\
\hline University of Virginia \\
\hline Virginia Commonwealth University \\
\hline University of Florida \\
\hline Mayo Clinic \\
\hline Vanderbilt University \\
\hline University of California, San Diego \\
\hline Duke University \\
\hline Capital Health \\
\hline University of Illinois \\
\hline University of Miami \\
\hline University of Cincinnati \\
\hline University at Buffalo \\
\hline University of Medicine and Dentistry of New Jersey \\
\hline University of Tennessee \\
\hline Stanford University \\
\hline Northwestern University \\
\hline Johns Hopkins \\
\hline Emory University \\
\hline Thomas Jefferson University \\
\hline Ohio State University \\
\hline University of Michigan \\
\hline Albany Medical Center \\
\hline Cedars Sinai \\
\hline Cleveland Clinic \\
\hline University of Pittsburgh Medical Center \\
\hline Massachusetts General Hospital \\
\hline New York University Medical Center \\
\hline Rush University Medical Center \\
\hline
\end{tabular}

familiar with the devices/equipment and were unable to catheterize a single major vessel. This suggests that incoming fellows likely may not have had enough time to practice these skills during training. This is somewhat surprising given the current requirements for certification for neurosurgery residents in the United States. In fact, it is mandated by the Residency Review Committee and the American Board of Neurological Surgery that neurosurgery programs have an endovascular rotation. This represents a potentially important opportunity for future enhancement in neurosurgery residency. There is little doubt that the potential lack of readiness of incoming fellows may limit their ability to fully benefit from advanced training during endovascular fellowship.

There are several possible explanations for the findings of this study, the most important of which is the somewhat rigid nature of the current neurosurgery residency training paradigm, which has been unable to fully keep pace with technological advancements not only in the endovascular field, but in other fields as well. Other reasons for the lack of preparedness of neurosurgery graduates include limited exposure to endovascular procedures, lack of mentor availability, duty hours restriction, and increased supervision requirements. Also, in some programs, endovascular procedures are performed by a neuroradiologist, which creates an additional barrier for exposure to endovascular procedures for neurosurgery residents. Some residents also feel that they will not need the endovascular skill set if they elect for a nonvascular fellowship or for private practice. Moreover, neurosurgery residents often assume that endovascular procedures are rather simple compared with open neurosurgical procedures and can be quickly mastered during fellowship. However, because the duration of most endovascular fellowships is 1 year, the learning curve is obviously steep. It is also well established that the more prepared the fellow is, the faster he or she can ascend the learning curve, allowing more time for refining necessary skills. ${ }^{9,11}$ Conversely, incoming fellows who did not acquire basic endovascular skills during residency will have to overcome a steeper learning curve and may not be able to achieve the expert phase or independently perform complex endovascular procedures by the completion of their fellowship. The relatively low degree of inclusion of endovascular techniques into neurosurgery curricula reminds us of the time-approximately 20 years ago-when spine instrumentation "belonged" to orthopedic surgeons and neurosurgery residents had little to no exposure to this vital technique. Today, it has become the norm for graduating neurosurgery residents to be proficient at spine instrumentation.

On the other hand, there was a high level of interest in academic and scholarly activities among graduating neurosurgeons. Additionally, there were high levels of communication skills among graduates, demonstration of respect for colleagues and ancillary staff, and ownership toward patients. This is a reminder of the quality of residents recruited by neurosurgery programs and their commitment to academics and advancement of surgical science in the United States.

\section{Limitations}

The present survey is limited by a less than perfectalthough high $(78 \%)$-response rate. Because the survey was anonymous, there is no way to determine whether nonrespondents differed from respondents. While the survey shows that graduates entering fellowship for the most part are in need of fellowship training, it did not address the skill sets of those graduates not entering fellowship.

Because the survey was anonymous, we could not study the correlation between the answers of fellowship program directors and residency program directors for the same trainee. In fact, the present study relies on the subjective opinions of the trainees' new mentors and provides no objective evidence that the trainees are actually deficient in any of these areas. This could introduce a potential bias, particularly in the case of trainees coming from other institutions (who likely account for the majority of the trainees). There is a possible natural bias against new trainees coming from other institutions, which may affect the opinions of fellowship program directors. A similar positive bias exists for one's own trainees. Having fellow- 
TABLE 3. Survey results

\begin{tabular}{|c|c|c|c|c|c|}
\hline Survey Item & $\begin{array}{c}\text { Strongly } \\
\text { Agree (\%) }\end{array}$ & $\begin{array}{c}\text { Agree } \\
(\%)\end{array}$ & $\begin{array}{l}\text { Neutral } \\
(\%)\end{array}$ & $\begin{array}{l}\text { Disagree } \\
(\%)\end{array}$ & $\begin{array}{c}\text { Strongly } \\
\text { Disagree }(\%)\end{array}$ \\
\hline Communicates effectively with patients & 30.43 & 52.17 & 8.7 & 8.7 & 0 \\
\hline Promptly comes in after hours to evaluate a sick patient & 36 & 36 & 20 & 8 & 0 \\
\hline Ownership towards his/her patients & 24 & 52 & 4 & 20 & 0 \\
\hline Treats the ancillary staff with respect & 32 & 56 & 12 & 0 & 0 \\
\hline Treats the residents and house staff with respect & 36 & 60 & 4 & 0 & 0 \\
\hline Professional behavior & 33.33 & 62.5 & 4.17 & 0 & 0 \\
\hline Knows the history and imaging & 22 & 44 & 16 & 20 & 0 \\
\hline Arrives to the endovascular suite prepared for the procedure & 20 & 36 & 24 & 20 & 0 \\
\hline Formulates a plan of action for patients & 24 & 36 & 20 & 20 & 0 \\
\hline Is familiar and comfortable with the devices & 8 & 12 & 24 & 40 & 16 \\
\hline Is familiar and comfortable with the angiography equipment & 8 & 16 & 20 & 40 & 16 \\
\hline Femoral access & 12 & 28 & 28 & 24 & 8 \\
\hline Vascular closure & 12 & 32 & 12 & 36 & 8 \\
\hline Catheterization of a major vessel & 8 & 12 & 24 & 32 & 24 \\
\hline 4-vessel angiogram safely & 8.7 & 4.35 & 13.04 & 43.48 & 30.43 \\
\hline Aneurysm or AVM feeder catheterization & 4 & 0 & 8 & 32 & 56 \\
\hline Take calls with only occasional consultation & 4 & 28 & 20 & 44 & 4 \\
\hline Cares for all postoperative issues on our patients & 8 & 40 & 16 & 36 & 0 \\
\hline Recognition of the neurovascular anatomy & 8 & 40 & 28 & 24 & 0 \\
\hline Can recognize anatomic variants & 8 & 32 & 24 & 32 & 4 \\
\hline Recognition and classification of neurovascular abnormalities & 8 & 36 & 28 & 24 & 4 \\
\hline Can identify early complications & 8.33 & 37.5 & 25 & 25 & 4.17 \\
\hline Understands pathophysiology of the disease & 20.83 & 45.83 & 29.17 & 4.17 & 0 \\
\hline Understands options for treatments and the role and indications for surgery & 16 & 40 & 28 & 16 & 0 \\
\hline $\begin{array}{l}\text { Is able to perform an initial outpatient interview and the design of the correct } \\
\text { workup }\end{array}$ & 20 & 64 & 16 & 0 & 0 \\
\hline $\begin{array}{l}\text { Is able to counsel patients regarding the differential diagnosis and the recom- } \\
\text { mendations for care }\end{array}$ & 12.5 & 62.5 & 16.67 & 8.33 & 0 \\
\hline Understands indications for procedure and work-up & 16 & 48 & 28 & 8 & 0 \\
\hline Grasp of alternatives for treatment and the areas of controversy & 16 & 36 & 28 & 16 & 4 \\
\hline Understands disease-specific post-surgical or post-radiographic follow-up & 20 & 36 & 28 & 16 & 0 \\
\hline Demonstrates clinical maturity & 20 & 60 & 12 & 8 & 0 \\
\hline Healthy curiosity in understanding underlying mechanisms & 28 & 52 & 12 & 8 & 0 \\
\hline Genuine interest in academic projects & 32 & 32 & 24 & 12 & 0 \\
\hline Is familiar with recent publications & 16 & 36 & 32 & 12 & 4 \\
\hline Self-initiative in conducting clinical research & 20 & 40 & 20 & 20 & 0 \\
\hline Compiles and analyzes data & 20 & 52 & 20 & 8 & 0 \\
\hline Understanding of research protocol design & 16 & 48 & 16 & 16 & 4 \\
\hline Understanding of basic statistics & 16 & 40 & 24 & 20 & 0 \\
\hline Writing a coherent manuscript & 16 & 52 & 20 & 12 & 0 \\
\hline Do you think that the survey adequately assesses the research question? & 16 & 56 & 16 & 8 & 4 \\
\hline
\end{tabular}

ship program directors provide separate answers regarding internal and external fellows may have partly accounted for this problem. The ideal way to study the preparedness of neurosurgery graduates would be to objectively assess their clinical and surgical performance with standardized tests.

Although the survey did not specifically assess the reasons for the potential gaps seen in training, it is likely that the lack of preparedness is mostly due to poor use of existing case material rather than a lack of case material. It would have been interesting to ask program directors the same set of questions regarding their graduating fellows to assess whether the deficiency resides in the residency training environment versus the trainee. 


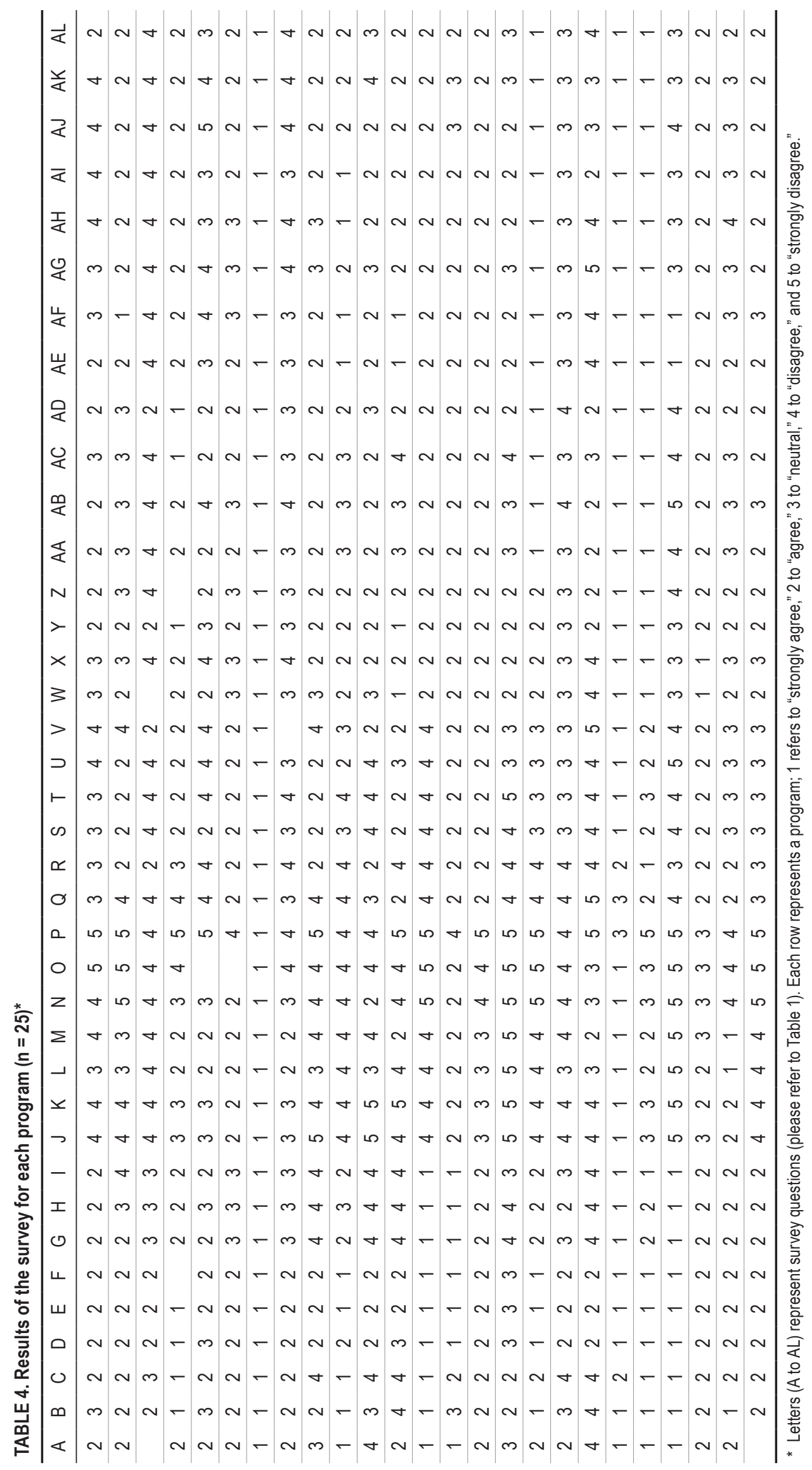




\section{Conclusions}

This study suggests potential gaps in the training of neurosurgery residents with regard to endovascular neurosurgery. These gaps may hinder the ability of neurosurgery graduates to benefit fully from postgraduate endovascular training. In an era of minimally invasive therapies, changes in residency curricula may be needed to keep pace with the ever changing and evolving field of neurosurgery.

\section{References}

1. Amenta PS, Dalyai RT, Kung D, Toporowski A, Chandela S, Hasan D, et al: Stent-assisted coiling of wide-necked aneurysms in the setting of acute subarachnoid hemorrhage: experience in 65 patients. Neurosurgery 70:1415-1429, 2012

2. Chalouhi N, Campbell P, Makke Y, Yadla S, Dumont AS, Gonzalez LF, et al: Treatment of complex intracranial aneurysms with a telescoping stent technique. J Neurol Surg A Cent Eur Neurosurg 73:281-288, 2012

3. Chalouhi N, Dumont AS, Tjoumakaris S, Gonzalez LF, Bilyk JR, Randazzo C, et al: The superior ophthalmic vein approach for the treatment of carotid-cavernous fistulas: a novel technique using Onyx. Neurosurg Focus 32(5):E13, 2012

4. Chalouhi N, Theofanis T, Jabbour P, Dumont AS, Gonzalez LF, Starke RM, et al: Endovascular treatment of posterior communicating artery aneurysms with oculomotor nerve palsy: clinical outcomes and predictors of nerve recovery. AJNR Am J Neuroradiol 34:828-832, 2013

5. Chalouhi N, Tjoumakaris S, Dumont AS, Gonzalez LF, Randazzo C, Gordon D, et al: Superior hypophyseal artery aneurysms have the lowest recurrence rate with endovascular therapy. AJNR Am J Neuroradiol 33:1502-1506, 2012

6. Chalouhi N, Tjoumakaris S, Starke RM, Hasan D, Sidhu N, Singhal S, et al: Endovascular stroke intervention in young patients with large vessel occlusions. Neurosurg Focus 36(1):E6, 2014

7. Gross BA, Du R: Cerebrovascular neurosurgery 2011. J Clin Neurosci 19:1344-1347, 2012

8. Jabbour P, Chalouhi N, Tjoumakaris S, Gonzalez LF, Dumont AS, Chitale R, et al: Pearls and pitfalls of intraarterial chemotherapy for retinoblastoma. J Neurosurg Pediatr 10:175-181, 2012

9. Kluger MD, Vigano L, Barroso R, Cherqui D: The learning curve in laparoscopic major liver resection. J Hepatobiliary Pancreat Sci 20:131-136, 2013
10. Mattar SG, Alseidi AA, Jones DB, Jeyarajah DR, Swanstrom LL, Aye RW, et al: General surgery residency inadequately prepares trainees for fellowship: results of a survey of fellowship program directors. Ann Surg 258:440-449, 2013

11. Schirmer BD, Schauer PR, Flum DR, Ellsmere J, Jones DB: Bariatric surgery training: getting your ticket punched. J Gastrointest Surg 11:807-812, 2007

12. Shakir HJ, Levy EI: The blunt truth behind coiling vs clipping: consumers as decision-drivers. Neurosurgery 74:E145-E146, 2014

13. Spetzler RF, McDougall CG, Albuquerque FC, Zabramski JM, Hills NK, Partovi S, et al: The Barrow Ruptured Aneurysm Trial: 3-year results. J Neurosurg 119:146-157, 2013 (Erratum in J Neurosurg 120:581, 2014)

14. Zanaty M, Chalouhi N, Starke RM, Tjoumakaris S, Gonzalez LF, Hasan D, et al: Endovascular treatment of cerebral mycotic aneurysm: a review of the literature and single center experience. Biomed Res Int 2013:151643, 2013

15. Zanaty M, Chalouhi N, Tjoumakaris SI, Rosenwasser RH, Jabbour PM: Endovascular management of cerebral aneurysm: review of the literature. Transl Stroke Res 5:199-206, 2014

\section{Author Contributions}

Conception and design: Jabbour, Chalouhi, Starke, Rosenwasser. Acquisition of data: Zanaty, Manasseh. Analysis and interpretation of data: Jabbour, Chalouhi, Zanaty, Tjoumakaris, Manasseh, Hasan, Bulsara, Starke, Lawson. Drafting the article: Jabbour, Chalouhi, Tjoumakaris, Hasan, Lawson, Rosenwasser. Critically revising the article: Jabbour, Chalouhi, Zanaty, Tjoumakaris, Manasseh, Hasan, Bulsara, Lawson, Rosenwasser. Reviewed submitted version of manuscript: Jabbour, Chalouhi, Tjoumakaris, Manasseh, Hasan, Bulsara, Starke, Lawson, Rosenwasser. Approved the final version of the manuscript on behalf of all authors: Jabbour. Statistical analysis: Starke. Administrative/ technical/material support: Chalouhi. Study supervision: Jabbour, Chalouhi.

\section{Correspondence}

Pascal M. Jabbour, Department of Neurological Surgery, Thomas Jefferson University Hospital, 901 Walnut St., 3rd Fl., Philadelphia, PA 19107. email: pascal.jabbour@jefferson.edu. 